\title{
KAPABILITAS PERSONEL PENGURUS PERSIT KARTIKA CHANDRA KIRANA CABANG XXV DIM 0809 KOORCAB REM O82 PD V/BRAWIJAYA
}

\author{
Yayuk Mudji Rahayu ${ }^{1)}$, *Harjito ${ }^{2),}$ Veril sella Marlita ${ }^{3)}$
}

1)Prodi Administrasi Publik, Fakultas Ilmu Sosial dan Publik, Universitas kadiri, Indonesia

2)Prodi Administrasi Publik, Fakultas Ilmu Sosial dan Publik, Universitas kadiri, Indonesia

*Email Korespondensi: verilsella0@gmail.com

\begin{abstract}
Abstrak
Tentara Nasional Indonesia Angkatan Darat (TNI AD) perlu memiliki pendamping yang senantiasa mengerti dan mendukung serta memberikan semangat dalam menjalankan tugas-tugas negara. Isteri-isteri prajurit TNI AD ini terwadahi dalam sebuah organisasi yaitu Persatuan Istri Prajurit Kartika Chandra Kirana (Persit KCK). Penelitian ini bertujuan untuk mengetahui kapabilitas Personel Pengurus Persit Kartika Chandra Kirana Cabang XXV Dim 0809 Koorcab Rem 082 PD V/Brawijaya. Dimana pada penelitian ini menggunakan teknik deskriptif dengan analisa kualitatif, sedangkan pendekatan pada penelitian ini adalah suatu pendekatan perspektif emik, yaitu pendekatan penelitian yang perolehan datanya dalam bentuk narasi, cerita detail, ungkapan dan bahasa asli hasil konstruksi para responden atau informan, tanpa ada evaluasi dan interpretasi dari peneliti. Sedangkan teknik pemilihan informan menggunakan purposive sampling dan snowball sampling. Hasil pada penelitina ini adalah Persit KCK memiliki lima asumsi indikator yang digunakan untuk melihat kapabilitas Persit yang terdiri dari kedisiplinan, motivasi, pengabdian, kerjasama, dan tanggung jawab, pada tataran implementasi asumsi indikator tidak menjadi asumsi lagi tetapi menjadi faktor pendukung yang nyata atau riel. Kelima faktor tersebut dalam implementasinya dapat dilaksanakan secara terintegrasi atau simultan dan dapat pula secara parsial sesuai dengan konteks dan dimensinya.
\end{abstract}

Kata Kunci: Kapabilitas; Persit KCK; Lima Indikator

Abstract
The Indonesian Army National Army (TNI AD) needs to have a companion who always
understands and supports and gives enthusiasm in carrying out state tasks. The wives of TNI AD
soldiers are contained in an organization, namely the Kartika Chandra Kirana (Persit KCK)
Soldier's Wives Association. This study aims to determine the capabilities of Persit Kartika
Chandra Kirana Management Personnel XXV Branch Dim 0809 Koorcab Rem 082 PD V I
Brawijaya. Where in this study using descriptive techniques with qualitative analysis, while the
approach in this study is an emic perspective approach, namely a research approach where data
collection is in the form of narratives, detailed stories, expressions, and the original language of
the constructs of the respondents or informants, without any evaluation and interpretation from
researchers. Meanwhile, the technique of selecting informants used purposive sampling and
snowball sampling. The results of this research are that KCK Persit has five indicator assumptions
that are used to see the capabilities of Persit which consist of discipline, motivation, dedication,
cooperation, and responsibility, at the level of implementation the indicator assumption is no


longer an assumption but becomes a real or real supporting factor. In its implementation, the five factors can be carried out in an integrated or simultaneous manner and can also be part of the context and dimensions.

Keywords: Capability; Persit KCK; Five Indicators

\section{PENDAHULUAN}

Tentara Nasional Indonesia (TNI) bertugas untuk menegakkan kedaulatan negara, mempertahankan keutuhan dan kedaulatan wilayah Negara Kesatuan Republik Indonesia (NKRI) dan melindungi bangsa Indonesia dari segala bentuk ancaman, tantangan, hambatan, dan gangguan (AGHT) negara baik yag datangnya dari dalam negeri (internal) maupun yang datang dari luar (eksternal) (Chalim \& Farhan, 2015). Oleh karena itu seorang prajurit Tentara Nasional Indonesia (TNI) adalah sangat berat, dan mereka harus siap menghadapi semuanya itu, baik dalam keadaan damai maupun perang sebagaimana ditegaskan pada Undang-Undang Nomor 3 Tahun 2002 Tentang Pertahanan Negara dan Undang-Undang Nomor 34 Tahun 2004 Tetang Tentara Nasional Indonesia (TNI) yang di dalamnya memuat Operasi Militer Unti Perang (OMP) dan Operasi Militer Selain Perang (OMSP). Faktor inilah yang membedakan dengan kehidupan masyarakat kebanyakan, dimana tuntutan tugas maupun budaya militer sangat kental dalam kehidupannya.

Agar dapat mengemban tugas-tugas yang dibebankan oleh negara kepada para insan prajurit tersebut dengan baik dan penuh rasa tanggung jawab, maka prajurit Tentara Nasional Indonesia Angkatan Darat (TNI AD) perlu memiliki pendamping yang senantiasa mengerti dan mendukung serta memberikan semangat dalam menjalankan tugas-tugas itu (Muzaqi, 2018) . Pada diri istri TNI AD yang sudah pasti tidak dapat dipisahkan kehadiran dan perannya dari kehidupan para prajurit. Hal ini adalah wajar karena sebelum dirinya dipersunting oleh anggota TNI AD, terlebih dahulu dihadapkan kepada Komandan Satuan dan Pejabat Pembinaan Mental serta melalui screnning yang ketat agar benar-benar memahami peran, tugas dan fungsi calon suaminya sebagai prajurit, dan dimana bagi sosok prajurit panggilan tugas untuk ibu pertiwi adalah segalagalanya. Sebagai isteri TNI AD, mereka memiliki peran yang besar yaitu sebagai pendamping suami, sebagai ibu rumah tangga, pengasuh dan pendidik putra putrinya, 
sebagai warga masyarakat, dan sebagai warga organisasi yang harus memahami tentang posisi dan perannya dalam organisasi. Oleh karena itu, tak hayal lagi bila keberhasilan suami tidak terlepas dari peran isteri.

Isteri-isteri prajurit TNI AD ini terwadahi dalam sebuah organisasi yaitu Persatuan Istri Prajurit Kartika Chandra Kirana (Persit KCK). Ketika menikah dengan prajurit TNI $\mathrm{AD}$ maka isteri prajurit tersebut secara otomatis menjadi anggota Persit KCK sehingga secara tidak langsung keanggotaan organisasi ini adalah wajib bagi isteri-isteri prajurit TNI. Kedudukan dan jabatan anggota Persit KCK dipengaruhi oleh pangkat dan jabatan suami (Prautami et al., 2016). Posisi dalam Persit KCK yang ditentukan oleh Pangkat dan Jabatan suami itu mereduksi diri anggota Persit KCK sebagai perempuan. Sebagai organisasi, Persit KCK memiliki banyak kegiatan yang dapat diikuti oleh anggota Persit KCK antara lain kegiatan kepengurusan, olahraga, senam aerobik, pertemuan anggota, arisan, posyandu, anjangsana dan latihan memasak, menari atau menjahit (Dewi, 2013).

Persit KCK yang berada dalam lingkungan militer dan keberadaannya tidak dapat dipisahkan dari organisasi TNI AD. Oleh karena itu pelaksanaan organisasi Persit KCK secara tidak langsung dipengaruhi oleh aturan-aturan yang berlaku dalam organisasi TNI AD. Salah satunya adalah penentuan Ketua dalam organisasi Persit KCK yang disesuaikan dengan pejabat tertinggi dalam satuan militer TNI AD. Penetapan jabatan dalam struktur organisasi Persit KCK berdasarkan pangkat suami ini menempatkan posisi formal anggota Persit KCK ke dalam bayang-bayang pangkat suami (Feliyanna, 2017). Sehingga anggota Persit yang pangkat suaminya tinggi dalam satuannya tidak memiliki pilihan lain dan harus menjalankan perannya dalam Persit KCK sesuai dengan pangkat suami. Pangkat dan jabatan dalam organisasi TNI AD dipandang sebagai hal yang penting dan sangat berpengaruh dalam kehidupan sehari-hari seperti dalam berperilaku dan berkomunikasi.

Melalui organisasi Persit KCK, perempuan tidak hanya diposisikan sebagai seorang isteri dan ibu yang baik tetapi juga sebagai anggota Persit KCK yang harus patuh kepada suami (Nurmasri, 2019). Pernikahan menghilangkan eksistensi diri perempuan sebagai dirinya seperti ketika menjadi anggota Persit KCK, seorang perempuan menghilangkan semua atribut yang melekat dalam dirinya seperti siapa dirinya, anak siapa dan asal mereka. Pangkat dan Jabatan suami ini memposisikan anggota Persit KCK dalam posisi 
formal sesuai dengan Pangkat dan Jabatan suami dimana anggota Persit KCK ini harus bertindak dan berkomunikasi harus disesuaikan dengan Pangkat dan Jabatan suami.

Organisasi Persit KCK dianggap sebagai organisasi yang sangat ketat dan kaku dimana cara berpakaian, cara berperilaku dan cara bicara anggotanya harus sesuai dengan aturan yang berlaku. Aturan yang mengatur anggota Persit KCK dalam berperilaku dan berbicara tidak tertulis dalam peraturan tertulis. Aturan-aturan ini diturunkan oleh senior (anggota Persit KCK lama) kepada juniornya (anggota Persit KCK baru) sebelum mereka menjadi istri prajurit TNI AD. Cara berbicara anggota Persit KCK disesuaikan dengan Pangkat dan Jabatan suami dan ketika berbicara dengan anggota Persit KCK yang lebih tinggi jabatannya, Perwira misalnya harus menggunakan bahasa yang sopan atau tata krama.

Sebagian besar anggota Persit KCK yang ditunjuk menjadi pengurus Persit KCK adalah anggota Persit KCK yang tidak bekerja karena dianggap anggota Persit KCK yang tidak bekerja lebih bertanggungjawab dan lebih banyak memiliki waktu dibandingkan dengan anggota Persit KCK yang bekerja. Disamping itu kebanyakan diduduki oleh para istri Perwira disesuaikan dengan Pangkat dan Jabatan suami. Demikian halnya dengan Persit KCK Cabang XXV Koorcab Rem 082 PD V/Brawijaya, juga memiliki tingkat kepengurusan baik Cabang maupu Ranting. Ketua Cabang tentu dijabat oleh istri Komandan Kodim (Dandim) dan Wakil Ketua Cabang dijabat oleh istri Kepala Staf Kodim (Kasdim), serta dibantu oleh Ketua Seksi dan Urusan yang dijabat oleh para isteri Perwira sesuai dengan strata jabatannya. Sedangkan untuk Ketua Ranting secara otomatis dijabat oleh istri dari Komandan Koramil (Danramil) sesuai dengan wilayah kerja masingmasing. Melihat dan mengingat bahwa kepengurusan dalam Persit KCK juga melaksanakan berbagai kegiatan baik yang bersifat administratif, sosial kemanusiaan maupun kegiatan lainnya diperlukan personel pengurus yang memiliki kapabilitas yang cukup memadai agar semua program dan kegiatan untuk mendukung tugas komando maupun kepengurusan tingkat atasnya seperti Koorcab (Korem) dan Pengurus Daerah (Kodam). Kapabilitas yang diperlukan misalnya kedisiplinan, motivasi, pengabdian, kerjasama, dan tanggung jawab. 


\section{TINJAUAN PUSTAKA}

Sebagai rujukan terhadap penelitian ini dan untuk memperkuat dari hasil pada penelitian ini, maka dipaparkan hasil tinjauan pustaka dalam konteks yang hampir sama yaitu penelitian yang dilakukan oleh Aryati Prautami tahun 2016 pada Jurusan Ilmu Komunikasi Fakultas Ilmu Sosial dan Ilmu Politik Universitas Diponegoro Semarang dengan judul Memahami Modalitas Perempuan Dalam Speech Codes Organisasi Persatuan Istri Prajurit TNI AD (Persit Kartika Chandra Kirana) (Prautami et al., 2016).

Adapun resensi dari hasil penelitian itu ialah persit merupakan organisasi yang beranggotakan istri-istri prajurit TNI AD. Keanggotaan dalam Persit adalah wajib dan jabatan anggota Persit dipengaruhi oleh pangkat suami. Posisi dalam Persit yang ditentukan oleh pangkat suami menghilangkan diri anggota Persit sebagai perempuan. Penelitian ini bertujuan untuk melihat bagaimana modalitas yang digunakan oleh istri-istri prajurit TNI dalam berinteraksi di dalam organisasi yang sangat berorientasi kepada pangkat dan jabatan suami. Setiap perempuan memiliki modal-modal yang dimilikinya untuk dapat berpartisipasi dalam kelompoknya, tidak terkecuali anggota persit yang menggunakan modal simbolik yaitu pangkat suami.

Penelitian ini dikaji menggunakan metode kualitatif dengan analisis etnografi kritis. Adapun teori dan konsep yang digunakan dalam penelitian ini adalah Speech Codes Theory (SCT) yang dikemukakan oleh Philipsen, konsep modalitas yang dikemukakan oleh Bourdieu, dan konsep kekuasaan dan subjektivitas yang dikemukakan oleh Foucault. Hasil penelitian menemukan bahwa dalam organisasi persit terdapat bahwa modalitas anggota persit yang terlihat adalah modal simbolik dan modal sosial. Selain itu terdapat tiga kode yang sangat terlihat yaitu codes of dignity (kode martabat), codes of loyalty (kode kepatuhan) dan codes of power (kode kekuasaan). Codes of dignity digunakan untuk menunjukkan posisi tertinggi seseorang dalam kelompoknya dimana dapat dilihat melalui pemilihan bahasa, panggilan yang digunakan anggota persit ketika berkomunikasi dengan anggota lain. Codes of loyalty digunakan untuk menunjukkan kepatuhan anggota persit dengan melihat topik pembicaraan yang cenderung dihindari ketika berbicara dengan anggota lain, perasaan ketika tidak mengikuti kegiatan persit dan keberanian dalam mengemukakan pendapat. Codes of power menunjukkan kekuasaan organisasi persit 
dalam mengikat bagi anggotanya untuk mengikuti kegiatan persit dan berbicara sesuai dengan jabatan dan pangkat suaminya. Ketiga kode ini menjelaskan bahwa anggota persit menggunakan modal simbolik yaitu pangkat suami.

Modal simbolik ini sangat kuat dalam organisasi persit dimana meskipun anggota persit menggunakan modal lain yang dimilikinya tetapi posisi anggota persit tetap saja yang dilihat dari pangkat suami. Jabatan suami ini membuat 13 anggota persit menggunakan modal sosial ketika berinteraksi dengan anggota persit lain yaitu modal sosial. Modal sosial ini digunakan untuk untuk menjaga hubungan baik dengan anggota ersit baik yang posisinya lebih tinggi atau sederajat. Anggota persit yang menggunakan modal sosial ini cenderung menghindari memberikan kritik atau saran kepada anggota persit yang posisinya lebih tinggi dibandingkan dirinya. Selain itu kedudukan anggota persit juga dapat terlihat ketika dirinya tergabung dalam kepengurusan persit. Anggota persit dapat menggunakan kemampuannya dalam bidang seni/olahraga dan pengalaman kerja untuk dapat ditunjuk sebagai pengurus persit.

\section{METODE PENELITIAN}

Jenis penelitian yang digunakan dalam penelitian ini adalah jenis penelitian deskriptif, yaitu suatu jenis penelitian yang bermaksud menggambarkan kejadian atau temuan-temuan data dan gejala-gejala yang ada dan yang terjadi berdasarkan fakta yang tampak atau sebagaimana adanya yang terjadi di lapangan pada saat penelitian dilaksanakan (Soendari, 2012).

Perspektif pendekatan penelitian dalam hal ini adalah cara pandang peneliti dalam memberikan tingkat kebebasan kepada responden dalam memberikan data atau informasi yang hendak disajikan. Pendekatan kualitatif yang dipilih oleh peneliti, dimana pendekatan ini adalah suatu pendekatan perspektif emik, yaitu pendekatan penelitian yang perolehan datanya dalam bentuk narasi, cerita detail, ungkapan dan bahasa asli hasil konstruksi para responden atau informan, tanpa ada evaluasi dan interpretasi dari peneliti. Data dalam bentuk cerita detail tersebut dapat diperoleh, karena teknik pengumpulan datanya adalah wawancara mendalam dan atau observasi, bukan kuesioner. Dengan demikian tingkat kebebasan perspektif emik yang diberikan kepada responden atau 
informan sangat tinggi. Sedangkan teknik pemilihan informan menggunakan purposive sampling dan snowball sampling (Sugiono, 2016). Informan pada penelitian ini ialah Pembina Harian, Ketua, Wakil Ketua dan Pengurus sesuai dengan bidang, tugas pokok dan fungsinya masing-masing. Teknik analisa data yang digunakan pada penelitian ini adalah teori Milles and Hubermen dalam (Saldana, 2014).

\section{HASIL DAN PEMBAHASAN}

Setelah mendapatkan informasi dan keterangan dari berbagai informan atau narasumber yang dianggap mewakili dan dapat dipertanggung jawabkan keakuratan datanya dan tervisualisasikan pada sub bab hasil penelitian. Maka selanjutnya dijabarkan dalam hasil dan pembahasan. Tinjauan pertama dilihat dari aspek kedisiplinan. Kedisiplinan mempunyai arti sebagai kepatuhan dan ketaatan seseorang kepada peraturan yang telah ditentukan dan dilakukan atas dasar kesadaran yang tulus ikhlas atau dedikasi dan loyalitas. Dedikasi wujudnya berbentuk kesanggupan dan kemauan para pengurus baik personal maupun kolektif menjalankan pekerjaan dengan ikhlas, rasa gembira dan bersemangat, tanpa dipengaruhi adanya tekanan dan pemaksaan oleh siapapun. Tercipta dan terbinanya disiplin dalam diri setiap pengurus tidak terlepas dari aspek mentalitas dari person yang bersangkutan.

Implementasi kedisiplinan personel pengurus Persit KCK Cabang XXV Dim 0809 terhadap tugas dan tanggung jawabnya, pada konteks realitanya secara umum adalah baik dimana dalam dirinya telah melekat dan tertanam kuat tentang apa yang dinamakan dengan disiplin sebagai imbas dari kebiasaan yang ada pada diri suami sebagai prajurit TNI Angkatan Darat. Jadi penegasannya bahwa pada prinsipnya masalah kedisiplinan personel pengurus Persit KCK Cabang XXV tidak ada masalah yang berarti karena hal ini sudah melekat dalam diri masing-masing sebagai konsekuensi dari isteri-isteri prajurit TNI Angkatan Darat. Adapun sebagian besar dari mereka adalah para isteri perwira baik di staf maupun komandan koramil. Kedisiplinan yang dimiliki oleh personel pengurus Persit KCK Cabang XXV mencakup disiplin kerja, disiplin waktu, disiplin berperilaku, disiplin anggaran, dan disiplin lainnya. 
Berikutnya tentang Motivasi yang merujuk pada dorongan diri pribadi maupun dari orang lain untuk melaksanakan tugas dan fungsinya dengan sebaik-baiknya sesuai dengan prosedur dan tatanan yang ada. Motivasi merupakan hal penting dalam implementasi semangat kerja pegawai. Hal ini cukup beralasan karena tanpa adanya motivasi, bekerja menjadi hampa atau kurang bergairah. Efek negatifnya bekerja menjadi lambat selesai, sering meleset dari target waktu yang telah ditentukan dan tidak efektif.

Untuk itu diperlukan kerja cerdas bagaimana membuat formula atau mengemas kepentingan-kepentingan setiap individu secara baik tanpa mengorbankan kepentingan lain yang lebih besar. Disinilah dibutuhkan kearifan membuat kebijakan dalam menata sumberdaya manusia agar pelaksanaan kegiatan organisasi dapat berjalan dengan baik dan lancar serta tatanan prosedur atau mekanisme kerja dengan mudah dapat dimengerti, dipahami, dan dilaksanakan oleh setiap personel dalam organisasi tersebut.

Terkait dengan aspek ini, pembina yang dalam hal ini adalah komandan kodim selalu memberikan motivasi baik langsung maupun tidak langsung. bahkan apabila mendapatkan kelebihan rejeki dan melalui ketua cabang, para pengurus diberikan insentif materiil berupa barang dan juga insentif moril dengan melaksanakan anjangsana sambil berekreasi. Melalui cara-cara motivsi seperti ini moril ibu-ibu tetap terjaga dan lebih bersemangat lagi dalam melaksanakan tugas dan pekerjaan yang dibebankan kepada masing-masing.

Perlu diketahui bahwa ibu-ibu yang ditunjuk menjadi pengurus ini tidak menerima imbalan materi apapun atau tidak menerima gaji atau upah. Mereka menerima penunjukkan ini semata-mata karena konsekuensi sebagai isteri prajurit TNI Angkatan Darat yang juga harus loyal kepada atasan dan juga bangga terhadap organisasi wadah isteri-isteri prajurit yaitu Persit Kartika Chandra Kirana.

Faktor selanjutnya yang mendukung kapabilitas personel pengurus Persit KCK Cabang XXV Dim 0809 adalah pengabdian dimana kesadaran dan kerelaan untuk bekerja tanpa pamrih dan tidak untuk mengharapkan imbalan berupa apapun dari siapapun atau dari manapun datangnya. Pengabdian adalah hal yang berhubungan dengan mengabdi. Mengabdi adalah suatu penyerahan diri suatu yang dianggap dilakukan dengan ikhlas bahkan diikuti pengorbanan. Pengabdian adalah perbuatan baik yang berupa pikiran dan 
pendapat ataupun tenaga sebagai perwujudan kesetiaan, cinta, kasih sayang, hormat, atau suatu ikatan dan semua itu dilakukan dengan ikhlas. Dalam konteksnya pengorbanan berarti suatu pemberian untuk menyatakan kebaktian, yang wujudnya berupa materi, perasaan, jiwa raga. Pengabdian dan pengorbanan bersinergi dalam langkah dan irama untuk mencapai satu tujuan tertentu.

Perlu diketahui bahwa pengurus Persit KCK Cabang XXV Dim 0809 ini tidak menerima upah atau gaji. Penugasan di organisasi isteri-isteri prajurit TNI Angkatan Darat adalah suatu kehormatan dan juga panggilan nurani untuk ikut serta mendukung tugas-tugas suami terutama dalam memberikan dorongan moril agar tugas dan tanggung jawabnya dilaksanakan dan diselesaikan dengan baik, maupun rasa ikut bertanggung jawab dalam rangka pembinaan terhadap isteri-isteri prajurit TNI Angkatan Darat Kodim 0809/Kediri. Oleh karena dasar itulah, maka penugasan sebagai pengurus dilaksanakan dengan penuh rasa pengabdian yang tulus ikhlas atau tanpa pamrih. Memang tidak dipungkiri bila sewaktu-waktu para pengurus mendapatkan imbalan materiil maupun non materiil, tetapi hal itu diterima dari pembina dalam hal ini Dandim 0809/Kediri atau dari ketua cabang, sifatnya sebagai ucapan terima kasih atau tali asih atas pengabdian, pengorbanan, loyalitas, dan dedikasinya kepada organisasi dan kesatuan.

Selanjutnya adalah faktor kerjasama yaitu suatu kondisi untuk saling mendukung atau membantu baik secara personal maupum antar bagian dalam melaksanakan pekerjaan, karena tidak ada satupun pekerjaan yang dapat dilaksanakan dan diselesaikan secara personal. Kerja yang dilakukan dalam sebuah tim lebih efektif daripada kerja secara individual atau personal. Ilustrasi yang disampaikan para nara sumber terpilih sebagai refresentasi pengurus lainnya memberikan penegasan atau kesimpulan bahwa kerjasama kepengurusan Persit KCK Cabang XXV Dim 0809 dketegorikan dengan baik dan menjadi salah satu faktor terwujudnya semangat kerja. Hal ini terlihat bahwa masingmasing personel pengurus menyadari dengan sepenuh hati bahwa pekerjaan-pekerjaan yang dibebankan kepada dirinya pelaksanaannya harus dengan melakukan kerjasama yang intensif dan efektif agar hasilnya menjadi efisien.

Sangatlah mustahil sebuah misi akan tercapai jika orang-orang yang ada di dalamnya memiliki tujuan yang berbeda. Guna mencapai pada sesuatu yang dicita- 
citakan bersama maka harus ada kesamaan persepsi dan juga kesamaan tujuan. Kerja yang dilakukan dalam sebuah tim lebih efektif daripada kerja secara individual. Kontribusi tiaptiap individu dapat menjadi sebuah kekuatan yang terintegrasi. Individu dikatakan bekerjasama jika upaya-upaya dari setiap individu tersebut secara sistematis terintegrasi untuk mencapai tujuan bersama. Dalam mencapai tujuan bersama, kerjasama memberikan manfaat yang besar bagi kerja tim, dan biasanya organisasi berbasis kerja tim memiliki struktur yang ramping sehingga organisasi akan bisa merespons dengan cepat dan efektif bila lingkungan cepat berubah.

Faktor yang terakhir adalah tanggung jawab dengan kesadaran manusia akan tingkah laku atau perbuatan baik yang disengaja maupun tidak disengaja, atau perbuatan manusia sebagai perwujudan kesadaran akan kewajiban. Pengurus Persit KCK Cabang XXV Dim 0809 yang mendapat kepercayaan atau mandat dari anggota untuk mengelola organisasi dan mendapatkan surat keputusan dari Pengurus PD V/Brawijaya. Adapun isi surat perintah tersebut juga tersebut kalimat yang bunyinya "melaksanakan perintah dengan penuh rasa tanggung jawab", karena itu personel hukumnya wajib melaksanakan surat perintah itu dalam tugasnya. Oleh karena itu, Pengurus Persit KCK Cabang XXV Dim 0809 dalam melaksanakan tugasnya dengan penuh rasa tanggung jawab. Mereka menjalankan tugas fungsinya sesuai dengan kaidah dan tata cara sebagaimana diatur dalam prinsip-prinsiporganisasi agar apa yang dilakukan dan dikerjakan senantiasa benar adanya dan baik hasilnya. Pelaksanaan dan tata kelola organisasi yang dilaksanakan oleh Persit KCK Cabang Dim 0809 tidak hanya dipertanggungjawabkan kepada anggota tetapi juga dipertanggungjawabkan kepada komandan satuan selaku pembina maupun kepada Koorcab Rem 082 dan PD V/Brawijaya. Tanggung jawab adalah sebuah tuntutan mutlak karena dengan komitmen itulah apa yang menjadi visi dan misinya dapat terlaksana dan terwujud dengan baik pula. Pengurus baik secara pribadi maupun bersama selalu memegang teguh prinsip kerja yang bertanggung jawab.

Disamping ke lima faktor pendukung sebagaimana terurai dengan jalas diatas, terdapat pula beberapa faktor yang menjadi penghambat terhadap kapabilitas personel pengurus Persit KCK Cabang XXV Dim 0809. Faktor-faktor tersebut seperti: fisik dan 
usia dimana para rata-rata berusia 45 tahun ke atas sehingga secara alamiah mengalami penurunan fisik yang tidak memungkinkan untuk dipacu kerja keras. Kemudian peran ganda, yaitu sebagai ibu rumah tangga, sebagai pengasuh putra-putrinya, sebagai warga masyarakat dimana peran-peran. Tersebut tidak dapat diabaikan begitu saja dan bahkan adakalanya peran itu dilakukan berangkai dalam waktu itu pula sehingga cukup menguras tenaga dan pikirannya. Ketiga adalah keterbatasan penguasaan teknologi informasi seperti excel dan email, sementara pengurus tidak ada yang menguasainya aplikasi program itu sehingga solusinya adalah bergantung pada tenaga administrasi yang diperbantukan di kantor persit atau staf dinas yang memahami program itu sehingga berpengaruh terhadap kecepatannya.

Dari analisis pembahasan terhadap asumsi indikator yang dipergunakan untuk mengetahui kapabilitas personel pengurus Persit Kartika Chandra Kirana Cabang XXV Dim 0809 Koorcab Rem 082 PD V/Brawijaya yang terdiri dari kedisiplinan, motivasi, pengabdian, kerjasama, dan tanggung jawab, pada tataran implementasi asumsi indikator tidak menjadi asumsi lagi tetapi menjadi faktor pendukung yang nyata atau riel. Kelima faktor tersebut dalam implementasinya dapat dilaksanakan secara terintegrasi atau simultan dan dapat pula secara parsial sesuai dengan konteks dan dimensinya. Akan tetapi juga terdapat faktor yang menjadi penghambat seperti fisik dan usia, peran ganda, dan keterbatasan kemampuan penguasaan teknologi. Terhadap faktor ini perlu adanya solusi dengan cara memilih dan menempatkan anggota Persit yang memiliki kemampuan untuk itu yang di-backup oleh anggota dari unsur dinas.

\section{KESIMPULAN DAN SARAN}

\section{Kesimpulan}

1. Kapabilitas personel pengurus Persit Kartika Chandra Kirana Cabang XXV Dim 0809 Koorcab Rem 082 PD V/Brawijaya diukur dengan mempergunakan lima asumsi sebagai parameternya, yaitu aspek kedisiplinan, aspek motivasi, aspek pengabdia, aspek kerjasama dan aspek tanggung jawab.

2. Dalam implementasi di lapangan berdasarkan hasil pengumpulan data dan analisis data diperoleh jawaban bahwa ke lima asumsi indikator yang diajukan dapat 
dilaksanakan secara nyata atau riel. Kelima faktor tersebut dalam implementasinya dapat dilaksanakan secara terintegrasi atau simultan dan dapat pula secara parsial sesuai dengan konteks dan dimensinya.

3. Selain faktor pendukung, terdapat juga faktor yang menjadi penghambat seperti fisik dan usia, peran ganda, dan keterbatasan kemampuan penguasaan teknologi. Terhadap faktor ini perlu adanya solusi dengan cara memilih dan menempatkan anggota Persit yang memiliki kemampuan untuk itu yang di-backup oleh anggota dari unsur dinas

\section{Saran}

1. Terhadap faktor yang menjadi pendukung kapabilitas personel pengurus Persit Kartika Chandra Kirana Cabang XXV Koorcab Rem 082 PD V/ Brawijaya yang terdiri dari lima faktor tersebut ke depan untuk dioptimalkan agar kinerja personel dan organisasi menjadi lebih baik dan berkualitas.

2. Sedangkan terhadap faktor penghambat perlu adanya solusi untuk pemecahannya melalui penunjukan dan penempatan sumberdaya anggota yang memiliki kapasitas kemampuan menangkap kemajuan teknologi sehingga dapat mempercepat kerja organisasi.

\section{REFERENSI}

Chalim, M. A., \& Farhan, F. 2015. Peranan Dan Kedudukan Tentara Nasional Indonesia (TNI) di dalam Rancangan Undang-Undang Keamanan Nasional di Tinjau dari Perspektif Politik Hukum di Indonesia. Dalam Jurnal Pembaharuan Hukum, 2(1).

Dewi, N. A. R. 2013. Studi Mengenai Keterampilan Sosial Anggota Persit Kartika Chandra Kirana Ranting Bs Vii Pusdik Bekang Pg Kodiklat Tni-Ad.

Feliyanna, J. 2017. Peran Istri Sebagai Motivator Terhadap Peningkatan Rasa Percaya Diri Suami Sebagai Prajurit Tni Di Satuan Batalyon Infanteri Raider 200/Bn (Bhakti Negara). Uin Raden Fatah Palembang.

Muzaqi, A. H. 2018. Perencaan Strategi Pemberdayaan Usaha Mikro Kecil Menengah (UMKM) Melalui Pendekatan Quadruple Helix (Studi pada Dinas Koperasi Usaha Mikro dan Perdagangan dan Kota Batu). Universitas Brawijaya.

Nurmasri, N. 2019. Pelaksanaan bimbingan keagamaan di kalangan Persatuan Istri 
Prajurit (PERSIT) Kartika Chandra Kirana di lingkungan TNI AD: Studi deskriptif di Komando Daerah Militer III/Siliwangi. UIN Sunan Gunung Djati Bandung.

Prautami, A., Dwiningtyas, H., \& Sos, S. 2016. Understanding Women's Capital in The Speech Codes of Indonesian Army's Wives Organization (Persit Kartika Chandra Kirana). Interaksi Online, 4(4), 1-11.

Saldana. 2014. Qualitative Data Analysis, A Methods Sourcebook. UI-Press.

Soendari, T. 2012. Metode Penelitian Deskriptif. Bandung, UPI. Stuss, Magdalena \& Herdan, Agnieszka, 17.

Sugiono, S. 2016. Metode Penelitian Kuantitatif, Kualitatif, dan $R \&$ D. Bandung: Alfabeta.

Undang-Undang Nomor 3 Tahun 2002 Tentang Pertahanan Negara Undang-Undang Nomor 34 Tahun 2004 Tetang Tentara Nasional Indonesia (TNI) 